\title{
Clinical outcome after laparoscopic and open abdominal myomectomy
}

\author{
Guri Baardstu Majak • Marit Lieng • Erik Qvigstad
}

Received: 5 July 2011 / Accepted: 11 August 2011 /Published online: 6 September 2011

(C) Springer-Verlag 2011

\begin{abstract}
This paper details a retrospective study evaluating long-term outcomes after laparoscopic and abdominal myomectomy, including improvement of abnormal vaginal bleeding, periodic blood loss, pelvic pain, and fertility. This is a retrospective study based on a postal questionnaire and the women's medical journal. A total of 233 women were identified as having had a myomectomy during the period 2003-2006 and were sent a postal questionnaire. The response rate was $70 \%$. After surgery, pain score was significantly reduced. The number of days with bleeding and the degree of discomfort due to bleeding was also reduced after the surgery. Among $31 \%$ of the women who stated infertility as a reason for the myomectomy, $52 \%$ became pregnant during the observational period of 4.5 years on average. Few studies report long-term outcomes after laparoscopic and abdominal myomectomy. Despite the limitations of this retrospective study, the results imply improvements regarding periodic pain, number of days with bleeding and discomfort due to bleeding after myomectomy.
\end{abstract}

Keywords Endoscopic surgery · Myoma · Pain · Infertility · Patient satisfaction

Electronic supplementary material The online version of this article (doi:10.1007/s10397-011-0699-z) contains supplementary material, which is available to authorized users.

G. B. Majak $(\bowtie) \cdot$ M. Lieng $\cdot$ E. Qvigstad

Department of Gynecology, Oslo University Hospital-Ullevål,

Kirkeveien 166,

0407 Oslo, Norway

e-mail: majg@uus.no

E. Qvigstad

University of Oslo, Norway,

Oslo, Norway

\section{Background}

Myomas are the most common benign tumor in women, with a reported incidence as high as $70-80 \%$ [1]. They are shown to be clinically apparent in up to $25 \%$ of all women, increasing to $30-40 \%$ of women over 40 years of age [2]. Myomas present with a variety of symptoms. In addition to abnormal vaginal bleeding, pelvic pain, and pressure-related symptoms, the reproductive function may also be compromised, leading to subfertility and early pregnancy loss [3].

The treatment options and modalities for myomas are increasing, but the outcome after different interventions have not been fully evaluated [4]. As yet, the treatment is mainly surgical including myomectomy or hysterectomy.

The impact of myomectomy on fertility is debated, and there is no consensus whether myomas cause infertility or if they simply are an association [5]. Studies including women undergoing assisted reproduction treatment, however, give strong evidence that submucous and intramural fibroids distorting the uterine cavity impair fertility and that removal improves the outcome in terms of pregnancies [6-8].

A study from 2003 performed by Seracchioli et al. [9] reports improvement in symptoms after myomectomy, but few studies have focused on relief of symptoms such as heavy bleeding and pelvic pain. Thus, the aim of this retrospective study was to analyze the clinical outcome after myomectomy, performed by laparotomy or laparoscopy, in terms of improvement in abnormal vaginal bleeding, periodic blood loss, pelvic pain, and fertility.

\section{Method}

Following an ethical approval in March 2009 (Regional Committee for Medical Research Ethics in Eastern Norway, 


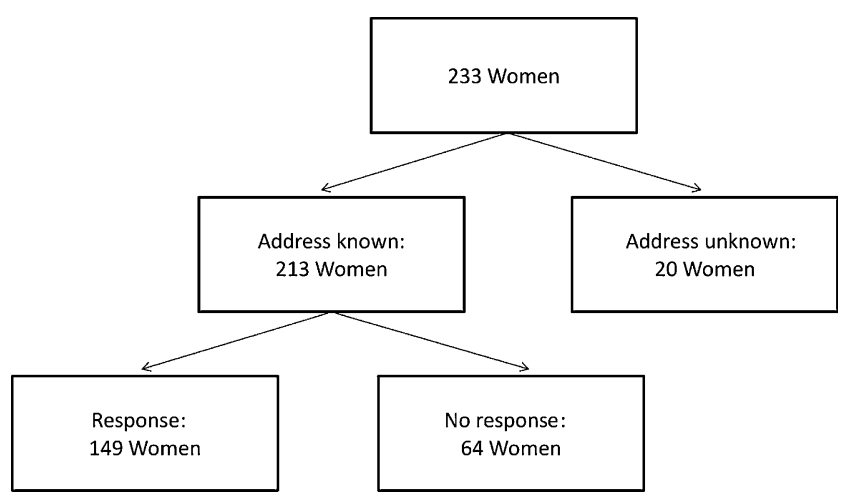

Fig. 1 Flow chart of study population

Ref: S-09128, 2009/2128), all women who were treated by myomectomy at the Department of Gynecology, Oslo University Hospital Ullevål from 2003 till 2006 were sent a questionnaire ("Electronic supplementary material"). A 4-year inclusion period was chosen in order to achieve a relatively large sample size. We consider the years before 2003 as being too long ago to ask women regarding their preoperative symptoms. The last years were omitted to ensure an acceptably long follow-up. Questions related to vaginal bleeding, pelvic pain, and fertility were raised for the preoperative period and the first two postoperative years, respectively. Standard 10-point visual analogue scales (VAS) were used to measure pain intensity and the extent to which bleeding gave discomfort. In addition, information about concomitant surgical procedures and postoperative complications were collected from the women's medical records.

Data were analyzed using SPSS for Windows (SPSS 17.0; SPSS, Inc. Chicago, IL, USA). All statistical tests were performed two-sided, with 5\% significance level. Normally distributed continuous data were analyzed using a two-sided independent samples Student's $t$ test and, when paired, the paired samples $t$ test. Categorical data were analyzed using Pearson's chi-square test.

\section{Findings}

A total of 233 women were sent the questionnaire. The 233 procedures were equally divided between the four inclusive years. Myomectomy was performed by laparoscopy in 161 women $(69 \%)$ and by laparotomy in 72 women $(31 \%)$. The mean age at time of surgery was 36.8 years. We were unable to reach 20 women due to unknown adresses. A total of 149 women returned the questionnaire, providing a response rate of $70 \%$ (Fig. 1).

The dominating indications stated for the myomectomy was pain $(43 \%)$, abnormal uterine bleeding $(36 \%)$, and infertility (31\%). A total of 18 women (12\%) stated other reasons, mostly pressure symptoms and/or that the procedure was recommended by a medical practitioner. There were 88 women $(59 \%)$ who stated two or more indications for having the myomectomy.

A total of 122 women $(82 \%)$ reported to have suffered from periodic pain before the myomectomy, with a mean score of 5.0 (SD 2.9) on a ten-point VAS. After myomectomy, the overall mean pain score was reduced to 3.0 (SD 2.8 ), giving a statistically significant mean pain reduction of 2.0 (SD 2.2; 95\% CI, 1.5, 2.5; $p<0.001$ ) (Table 1). Women who stated pain as an indication for myomectomy (64 women) had a higher mean pain reduction than women not stating pain as indication (Table 1). In addition, 52 $(35 \%)$ of the women stating pain as indication for myomectomy reported to be completely pain-free after the myomectomy. A total of 45 women reported absence from work due to menstrual pain before the myomectomy, which was reduced to 19 women after the myomectomy.

Self-reported preoperative menstrual data were available for all 149 women who returned the questionnaire. Mean days with bleeding were reduced for all women after the myomectomy, with the highest reduction for women with bleeding as indication for the myomectomy (Table 2).

In all 149 women, the mean degree of discomfort caused by vaginal bleeding, scored on a ten-point VAS, was significantly reduced after the myomectomy. The highest reduction was seen in women stating bleeding as indication for the myomectomy (Table 2).

During the follow-up period, 58 out of the 149 responders conceived and 51 women gave birth. A total of 29 women delivered by cesarean section. Ten women reported that complications occurred during their pregnancy and/or delivery, but except for one pre-labor rupture of the uterus, no complications seemed related to the previous myomectomy.

Table 1 Intensity of pelvic pain before and after the myomectomy as measured by a standard ten-point visual analogue scale

\begin{tabular}{|c|c|c|c|c|}
\hline & $\begin{array}{l}\text { VAS pain score before } \\
\text { myomectomy, mean (SD) }\end{array}$ & $\begin{array}{l}\text { VAS pain score after } \\
\text { myomectomy, mean (SD) }\end{array}$ & $\begin{array}{l}\text { Difference pain score, } \\
\text { mean (SD); } 95 \% \text { CI }\end{array}$ & $p$-value \\
\hline Overall pain intensity $(n=122)$ & $5.0(2.9)$ & $3.0(2.8)$ & $2.0(3.0) ; 1.5,2.5$ & $<0.001$ \\
\hline $\begin{array}{l}\text { Pain intensity in women with pain as } \\
\text { indication for myomectomy }(n=64)\end{array}$ & $5.9(2.9)$ & $3.5(3.0)$ & $2.4(3.7) ; 1.5,3.3$ & $<0.001$ \\
\hline $\begin{array}{l}\text { Pain intensity in women without pain } \\
\text { as indication }(n=58)\end{array}$ & $4.2(2.7)$ & $2.6(2.5)$ & $1.6(2.2) ; 1.1,2.1$ & $<0.001$ \\
\hline
\end{tabular}


Table 2 Days of bleeding and degree of discomfort due to bleeding before and after the myomectomy

\begin{tabular}{|c|c|c|c|c|}
\hline & $\begin{array}{l}\text { Before myomectomy, } \\
\text { mean (SD) }\end{array}$ & $\begin{array}{l}\text { After myomectomy, } \\
\text { mean (SD) }\end{array}$ & $\begin{array}{l}\text { Difference, mean } \\
\text { (SD); } 95 \% \text { CI }\end{array}$ & $p$-value \\
\hline Overall days of bleeding $(n=149)$ & $5.9(2.2)$ & $4.9(1.8)$ & $1.0(2.2) ; 0.7,1.5$ & $<0.001$ \\
\hline $\begin{array}{l}\text { Days of bleeding in women with bleeding } \\
\text { as indication }(n=54)\end{array}$ & $7.4(2.6)$ & $5.1(2.3)$ & $2.3(2.7) ; 1.5,3.2$ & $<0.001$ \\
\hline Degree of discomfort due to bleeding $(n=149)$ & $5.3(2.6)$ & $3.3(2.6)$ & $1.9(3.2) ; 1.3,2.5$ & $<0.001$ \\
\hline $\begin{array}{l}\text { Degree of discomfort due to bleeding in women } \\
\text { with bleeding as indication }(n=54)\end{array}$ & $8.3(1.7)$ & $3.6(2.9)$ & $4.6(3.4) ; 3.6,5.7$ & $<0.001$ \\
\hline
\end{tabular}

Out of the responders, $46(31 \%)$ reported infertility as indication for the myomectomy. The mean age for these women was 36.0 years at the time of surgery and the median observational time was 4.5 years (range 2.06.0 years). Out of these 46 women, 24 conceived and 20 gave birth, resulting in a pregnancy rate of $52 \%$ and a live birth rate of $45 \%$, respectively.

A high proportion of the included women $(n=122,82 \%)$ reported being satisfied or very satisfied with the myomectomy. There was no difference in satisfaction related to the indication for myomectomy or the surgical approach (Fig. 2).

Immediate postoperative complications occurred in 11 out of the 149 responders (7\%). The complication rate was $9 \%$ in laparoscopic procedures and $7 \%$ in open procedures, respectively. The complications were as follows: accidental morcellation of the bowel in one woman, peroperative bleeding requiring blood transfusion in three women, postoperative abdominal infection/ intraabdominal abscess in five women and urinary tract infection in two women. In addition, one woman reported uterine rupture which may represent a late complication to the surgery.

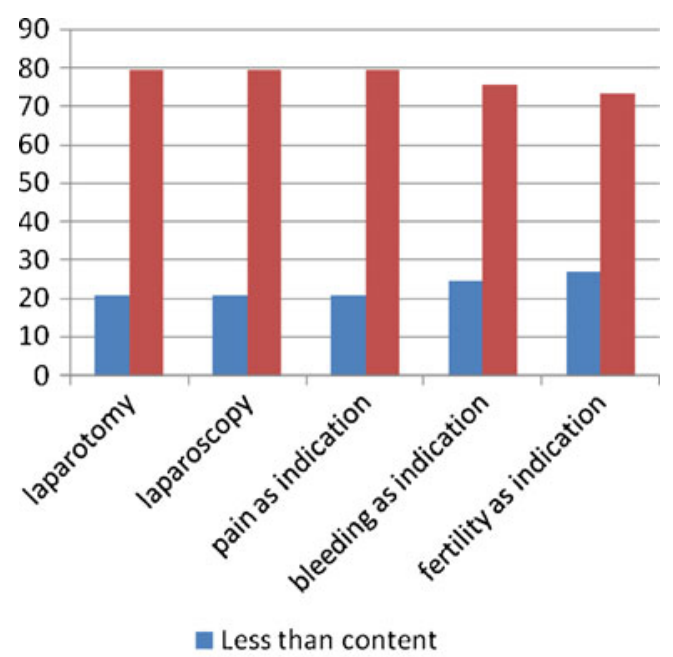

- Satisfied or very satisfied

Fig. 2 Satisfaction related to surgical procedure and stated indication

\section{Conclusions}

The results of our study indicate that the women who underwent myomectomy experienced significantly reduced periodic pelvic pain after the procedure. They also reported reduced number of days with vaginal bleeding and significantly reduced discomfort due to bleeding. The overall patient satisfaction was very high after the procedure, with $82 \%$ reporting to be very satisfied or satisfied postoperatively.

Although all women reported significantly reduced periodic pain after myomectomy, the largest reduction of pain score was observed in women who reported pain as indication for the myomectomy. Eighty-eight women stated two or more indications for having the myomectomy, and the combination of abnormal uterine bleeding and pain was the most common. This supports a previous theory suggesting that increased blood flow may be associated with dysmenorrhea, especially if there is passage of blood clots [10]. Myomas are also associated with adenomyosis, which again is associated with menstruational pain [10]. There is reason to believe that most of the women treated by laparoscopic or abdominal myomectomy suffered from intramural or subserosal myomas since submucosal myomas are preferably treated surgically by hysteroscopic resection. Wegienka et al. have shown that intramural and subserosal myomas had the same tendency to cause menorrhagia as the submucosal ones [11].

The exact mechanism by which myomas may cause excessive bleeding is unknown, though abnormal vaginal bleeding, and usually menorrhagia, is stated as the most common symptom reported by women with myomas [12]. The relation between increased periodic blood loss and myomas may be caused by factors such as increased endometrial surface area, increased vascularity of the uterus, interference with the normal uterine contractility and pressure, and impingement on the uterine venous system causing the dilatation of venules within the myometrium and endometrium [13-15]. Furthermore, dysregulation of local vasoactive growth factors is thought to promote vasodilatation [16]. When enlarged venules are disrupted during the periodical bleeding, the bleeding from dilated venules may exceed the usual hemostatic mechanisms [17]. Our findings of reduction of periodic blood loss after myomectomy 
substantiate such theories, and our results indicate that myomectomy shortened the menstrual period and significantly reduced discomfort related to periodic bleeding.

When all other causes of infertility are excluded, it is generally thought that myomas may be responsible for infertility in only $2-3 \%$ of infertility cases [17]. In our study, the women reporting infertility as indication for the myomectomy had a postoperative pregnancy rate of $52 \%$. The 5 -year review by Olufowobi et al. after myomectomy reported that the spontaneous pregnancy group had a pregnancy rate of $46 \%$, which is approximately the same as the findings in our study [12]. Literature reviews imply that submucosal myomas have a strong association with lower ongoing pregnancy rates and decreased implantation, while women with intramural myomas experience more miscarriages. Data from women undergoing assisted reproduction technology (ART) suggest that removal of submucosal myomas and intramural myomas that distort the uterine cavity improves the fertility outcome, but the cause-effect relationship is poorly understood [18]. A limitation in our study is the lack of information regarding ART in the reported pregnancies.

The strength of our study is its originality, reporting the beneficial outcome of relatively commonly performed procedures, which previously were scarcely evaluated. Furthermore, the sample size is relatively large. The major limitation of the study is that we have no information about the size, site, and number of myomas removed in each patient. Prospective, randomized studies are needed to assess the impact of these factors regarding the effect of myomectomy.

Another limitation is the retrospective nature of this study. However, while women may not have been able to recall their preoperative symptoms with great precision, we believe that they were able to present a reasonably accurate view of the whole experience from the pre- to postoperative period, and therefore the change in symptoms is likely to reflect improvements or deteriorations. The response rate was $70 \%$, and we were not able to reach 20 patients because of unknown address. The reported treatment efficacy could therefore be considered as overestimated. The information from the womens medical journals and the questionnaire implies that this is a heterogeneous group, and the reported improvements are significant.

In conclusion, this retrospective study indicates improvements regarding periodic pain, number of days with bleeding, and discomfort due to bleeding after myomectomy. Despite the limitations described, we believe that the significant benefits observed after myomectomy are promising and should be proven in future prospective studies.
Conflicts of interest The authors report no conflicts of interest. The authors alone are responsible for the content and writing of the paper.

\section{References}

1. Baird DB, Dunson DB, Hill MC, Cousins D, Scechtman JM (2003) High cumulative incidence of uterine leiomyoma in black and white women: ultrasound evidence. Am J Obstet Gynecol 188 (1):100-107

2. Buttram VC Jr (1986) Uterine leiomyomata-aetiology, symptomatology and management. Prog Clin Biol Res 225:275-296

3. Stewart EA (2001) Uterine fibroids. Lancet 357:293-298

4. Istre O (2008) Management of symptomatic fibroids: conservative surgical treatment modalities other than abdominal and laparoscopic myomectomy. In: Arulkumaran S, Manyonda IT (eds) Best practice and research, vol 22, 4. Elsevier, New York, pp 735-747

5. Khaund A, Lumsden M (2008) Impact of fibroids on reproductive function. In: Arulkumaran S, Manyonda IT (eds) Best practice and research, vol 22, 4. Elsevier, New York, pp 749-760

6. Keltz M, Varasteh N, Levin B, Neuwirth R (1998) Pregnancy rates following hysteroscopic polypectomy, myomectomy and a normal cavity in infertile patients. Prim Care Update Ob Gyns 5(4):168

7. Connolly G, Doyle M, Barrett T, Byrne P, De Mello M, Harrison RF (2000) Fertility after abdominal myomectomy. J Obstet Gynaecol 20:418-420

8. Campo S, Campo V, Gambadauro P (2003) Reproductive outcome before and after laparoscopic or abdominal myomectomy for subserous or intramural myomas. Eur J Obstet Gynecol Reprod Biol 110:215-219

9. Seracchioli R, Colombo FM, Bagnoli A, Govoni F, Missiroli S, Venturoli S (2003) Laparoscopic myomectomy for fibroids penetrating the uterine cavity: is it a safe procedure? BJOG 110 (3):236-240

10. Lippman SA, Warner M, Samules S, Olive D, Vercellini P, Eskenazi B (2003) Uterine fibroids and gynaecologic pain symptoms in a population based study. Fertil Steril 80:1488-1494

11. Wegienka G, Baird DD, Hertz-Picciotto I, Harlow SD, Steege JF, Hill MC et al (2003) Self-reported heavy bleeding associated with uterine leiomyomata. Obstet Gynecol 101:431-437

12. Olufowobi O, Sharif K, Papaionnou S, Neelakantan D, Mohammed H, Afnan M (2004) Are the anticipated benefits of myomectomy achieved in women in reproductive age? A 5-year review of the results at a UK tertiary hospital. J Obstet Gynecol $24: 434-440$

13. Sehgal N, Haskins AL (1960) The mechanism of uterine bleeding in the presence of fibromyomas. Am Surg 26:21-33

14. Farrer-Brown G, Beilby JO, Tarbit MH (1970) The vascular pattern in myomatous uteri. J Obstet Gynecol Br Commonw 77:967-975

15. Farrer-Brown G, Beilby JO, Tarbit MH (1971) Venous changes in endometrium of myomatous uteri. Obstet Gynecol 38:743-751

16. Stewart EA, Nowak RA (1996) Leiomyoma-related bleeding: a classic hypothesis updated for the molecular era. Hum Reprod Update 2:295-306

17. Buttram VC Jr, Reiter RC (1981) Uterine leiomyomata: etiology, symptomatology and management. Fertil Steril 36:433-445

18. Klatsky PC, Tran ND, Caughey AB, Fujimoto VY (2008) Fibroids and reproductive outcomes: a systematic literature review from conception to delivery. Am J Obst Gyn 198(4):357-366 